\title{
Hafnium (IV) oxide obtained by atomic layer deposition (ALD) technology promotes early osteogenesis via activation of Runx2-OPN-mir21A axis while inhibits osteoclasts activity
}

\author{
A. Seweryn ${ }^{1}$, M. Alicka², A. Fal ${ }^{3}$, K. Kornicka-Garbowska²,4, K. Lawniczak-Jablonska' , M. Ozga' , P. Kuzmiuk' , \\ M. Godlewski ${ }^{1}$ and K. Marycz $z^{2,3,4^{*}}$
}

\begin{abstract}
Background: Due to increasing aging of population prevalence of age-related disorders including osteoporosis is rapidly growing. Due to health and economic impact of the disease, there is an urgent need to develop techniques supporting bone metabolism and bone regeneration after fracture. Due to imbalance between bone forming and bone resorbing cells, the healing process of osteoporotic bone is problematic and prolonged. Thus searching for agents able to restore the homeostasis between these cells is strongly desirable.

Results: In the present study, using ALD technology, we obtained homogeneous, amorphous layer of hafnium (IV) oxide $\left(\mathrm{HfO}_{2}\right)$. Considering the specific growth rate $(1.9 \AA / \mathrm{cycle})$ for the selected process at the temperature of $90^{\circ} \mathrm{C}$, we performed the $100 \mathrm{~nm}$ deposition process, which was confirmed by measuring film thickness using reflectometry. Then biological properties of the layer were investigated with pre-osteoblast (MC3T3), pre-osteoclasts (4B12) and macrophages (RAW 264.7) using immunofluorescence and RT-qPCR. We have shown, that $\mathrm{HfO}_{2}$ (i) enhance osteogenesis, (ii) reduce osteoclastogenesis (iii) do not elicit immune response and (iv) exert anti-inflammatory effects.
\end{abstract}

Conclusion: $\mathrm{HfO}_{2}$ layer can be applied to cover the surface of metallic biomaterials in order to enhance the healing process of osteoporotic bone fracture.

Keywords: Hafnium (IV) oxide, Atomic layer deposition, Osteoblasts, Osteoclasts, Biomaterials, Osteoporosis

\section{Background}

Regenerative medicine is a fast-growing field that is being successfully applied in traumatology or reconstructive surgery, where it is showing to be a promising avenue for the treatment of elderly patients [1]. Due to rapid aging of

\footnotetext{
*Correspondence: krzysztof.marycz@upwr.edu.pl

2 Department of Experimental Biology, Faculty of Biology and Animal

Science, Wrocław University of Environmental and Life Sciences, Norwida 27B, 50-375 Wrocław, Poland

Full list of author information is available at the end of the article
}

populations, there is an urgent need to develop personalized therapies for aged-related diseases. One of the most common disorder affecting elderly population worldwide is osteoporosis (OP) which deteriorates bone mass and architecture [2]. In accordance to recent data, around 200 million people suffer from OP and 8.9 million fractures are caused by the disease [3]. Besides being a great concern of the health care system, OP comes with economic burden. In the United States of America, costs of OPrelated fractures is estimated to $\$ 13.8$ billion. Therefore,

c) The Author(s) 2020. This article is licensed under a Creative Commons Attribution 4.0 International License, which permits use, sharing, adaptation, distribution and reproduction in any medium or format, as long as you give appropriate credit to the original author(s) and the source, provide a link to the Creative Commons licence, and indicate if changes were made. The images or other third party material in this article are included in the article's Creative Commons licence, unless indicated otherwise in a credit line to the material. If material is not included in the article's Creative Commons licence and your intended use is not permitted by statutory regulation or exceeds the permitted use, you will need to obtain permission directly from the copyright holder. To view a copy of this licence, visit http://creativeco mmons.org/licenses/by/4.0/. The Creative Commons Public Domain Dedication waiver (http://creativecommons.org/publicdomain/ zero/1.0/) applies to the data made available in this article, unless otherwise stated in a credit line to the data. 
OP represents not only clinical and public issue but due to significant morbidity, mortality and health care costs it represents a major challenge for world economies.

Metallic implants have been utilized for different medical purposes including orthopedics for short as well as long term fixations since many years [4]. So far, the most frequently applied metallic materials in traumatology are stainless steel (SS), titanium or cobalt alloys [5]. For the fixation of simple fractures, usually SS is applied due to much lower costs than titanium alloys. However, due to its corrosive nature and risk of allergic reaction due to released ions, SS is recommended for short term fixation procedures [6]. In turn, titanium alloys are characterized by good corrosion resistance and biocompatibility in contact with human body fluids, but their biomechanical properties are less attractive, when compared to SS. Metallic materials seem to be still an irreplaceable in reconstructive surgery, although there are many reports indicating on their disadvantages including postoperative complications, distortion of post-operative metallic screws and inflammatory reactions [5].

Methods have been devised to modify and improve the properties of the base material in order to enhance the medical outcome of the therapy. One of the approach to enhance the properties of metallic materials is their surface modifications by the application of various techniques including Atomic Layer Deposition (ALD). This technique allows to deposit a thin film onto various materials, such as metal, glass and polymers [7]. The ALD method is based on sequential introduction of selected chemical compounds (precursors) into the reaction chamber. As a result of chemical reactions between precursors on the substrate, a thin film grows closely attached to the substrate. The introduction of selected precursors is separated by the neutral gas fraction e.g. argon or nitrogen, which allows removal of the unreacted precursor molecules and reaction by-products from the reactor chamber [8]. Thickness of a newly formed layer is controlled by number of ALD cycles and the growth process is self-limiting. In optimal case only one monolayer may be grown during one ALD cycle (precursor doses separated by purging of a growth chamber). Such deposition model allows precise control of the layer thicknesses. The required thickness is controlled by estimated number of the ALD cycles [9]. One of the biggest advantages of the ALD technique is ability to obtain highly reproducible, homogenous coatings while the deposition process does not depend on source of the substrates [10]. What is more, the growth process can be performed even at room temperature [11], which allows to consider future functionalization of biological factors, even such as cells or drugs [12, 13]. Despite low temperature of growth, the resulting layers are of high quality and are highly homogeneous. Due to its multiple advantages, ALD technology allows to obtain nanolayers characterized by specific biological properties. In particular, the ALD method leads to deposit of transition metal oxides. Recently our group reported that zirconium (IV) oxide $\left(\mathrm{ZrO}_{2}\right)$ thin films, deposited using ALD technology, improve metabolic as well as pro-osteogenic potential of bone precursor cell line through activation of miR-21 [14], which become an motivation for the present study.

Intelligent, smart scaffolds, including metallic materials, dedicated for osteoporotic bone regeneration, should be designed to represent not only great biocompatibility but also bioactivity in order to modulate microenvironment of surrounding tissue $[15,16]$. It is strongly required for a scaffold to enhance osteogenesis via promotion of osteoblast differentiation, while silencing osteoclasts differentiation and maturation. What is more, in the course of bone fracture healing triggering of intrinsic, natural processes in order to reduce inflammation is strongly required. For that reason, we decided to investigate whether hafnium (IV) oxide $\left(\mathrm{HfO}_{2}\right)$ layer can be utilized in the fabrication of personalized biomaterials for elderly patients during OP fractures. In presented paper, we analyzed physicochemical and biological properties of the layer revealing its pro-osteogenic properties. Obtained results shed a promising light for $\mathrm{HfO}_{2}$ future application in the field of nanometric coatings for biomedical applications.

\section{Results}

\section{Physicochemical analysis}

The X-ray photoelectron spectroscopy (XPS) analysis (Fig. 1) indicated that $\mathrm{HfO}_{2}$ was formed on the surface during the ALD growth process. Only oxygen $(\mathrm{O})$ and hafnium (Hf), in the ratio of 2.2, and carbon (C) were detected (Fig. 1a) [17]. The hhigh $C$ content (about 31\%) and oxygen surplus probably comes from atmospheric pollution. The oxygen line analysis (Fig. 1c) confirms that many of oxygen atoms (about 75\%) were bound with hafnium atoms with the binding energy equal to $530.6 \mathrm{eV}$ [18]. The $25 \%$ of the oxygen line is answering the surface contamination with the value of binding energy $532.6 \mathrm{eV}$.

The results of depth profiling are presented in Fig. $1 \mathrm{~b}$. The concentration of elements was measured after $5,10,15,20$ and $25 \mathrm{~min}$ of sputtering. The Hf $4 \mathrm{f}$ lines $(19.6 \mathrm{eV})$ (Fig. 1c) were analyzed to estimate the hafnium content. [18] Unlike the more surface sensitive Hf $4 \mathrm{~d}$ lines $(213.8 \mathrm{eV})$, the Hf $4 \mathrm{f}$ lines come from less strongly bound electron shells, therefore photoelectrons have higher kinetic energy and released from larger depths, which gives more accurate results of measurements minimizing disorder introduced by the sputtering. The final tests depth was estimated to be about 35-40 nm. 
Therefore, we can claim the homogeneity of the element's distribution in the coating. After the first $5 \mathrm{~min}$ of sputtering, the carbon content dropped to 10 at \% and remained constant in subsequent measurements. The ratio of oxygen atoms to hafnium atoms was also stable at the level 1.6. This change in respect to as received film results from the preferential sputtering of oxygen what is seen in the change of $\mathrm{Hf} 4 \mathrm{f}$ line during spattering (Fig. 1e). After 5 min sputtering the $\mathrm{Hf} 4 \mathrm{f}$ line bounded to 7 oxygen atoms (metal centres in $\mathrm{HfO}_{2}$ are coordinated by seven oxygen atoms [11]) simulated by the mixed Gaussian $(40 \%)$ and Laurencin (60\%) function is broadening from FWHM equal to $1.4 \mathrm{eV}$ to $1.6 \mathrm{eV}$. Moreover, the second doublet ( $20 \%$ of the line area) should be added to account for the $\mathrm{Hf}$ atoms bounded to less than 7 oxygen atoms with FWHM equal to $2.2 \mathrm{eV}$, what evidences the disorder introduced during the sputtering [19].

The thickness of the oxide layer was determined by comparing the reflection spectrum of white light from the substrate $(\mathrm{Si})$ to the reflection spectrum of light from a $\mathrm{HfO}_{2}$ layer deposited on the silicon substrate. A $100 \mathrm{~nm}$ thick $\mathrm{HfO}_{2}$ layer was successfully deposited onto the substrate. Additionally, lack of an X-ray diffraction (XRD) signal confirms the amorphous nature of the films. XRD can only occur on the ordered structure of the atoms.

The morphology was investigated using Atomic Force Microscope (AFM) (Fig. 1f, g). Surface images were made for areas of the size $10 \mu \mathrm{m} \times 10 \mu \mathrm{m}$ (Fig. $1 \mathrm{~g}$ ), $2 \mu \mathrm{m} \times 2 \mu \mathrm{m}$ (Fig. 1f) and $1 \mu \mathrm{m} \times 1 \mu \mathrm{m}$. The surface roughness of the layer was determined from the obtained AFM data. Ra is an arithmetic average of the absolute values of the surface height deviations and $\mathrm{Rq}$ is the root mean square (RMS) average of height values. The calculated surface roughness $\mathrm{Ra}$ is $0.422 \mathrm{~nm}, 0.537 \mathrm{~nm}$ and $0.536 \mathrm{~nm}$ while $\mathrm{Rq}$ is equal to $0.535 \mathrm{~nm}, 0.678 \mathrm{~nm}$ and $0.675 \mathrm{~nm}$ respectively for $100 \mu \mathrm{m}^{2}, 4 \mu \mathrm{m}^{2}$ and $1 \mu \mathrm{m}^{2}$ area. Uniformly distributed peaks can be observed on the surface of the layer there. Their maximal peak-to-valley value is only $6.5 \mathrm{~nm}$ over $100 \mu \mathrm{m}^{2}$ area. Such a small maximum value of the height of irregularities occurring on the surface indicates uniform growth of the layer and lack of contamination on the surface.

\section{Hafnium (IV) oxide $\left(\mathrm{HfO}_{2}\right)$ significantly affects proliferation activity and viability of osteoblast precursors and pre-osteoclasts}

The effect of $\mathrm{HfO}_{2}$ on proliferation activity pre-osteoblasts (MC3T3-E1) and pre-osteoclasts (4B12) was evaluated with resazurin based assay. Cell proliferation was monitored during $144 \mathrm{~h}$ of culture in normal condition or in the presence of $\mathrm{HfO}_{2}$. We noted that $\mathrm{HfO}_{2}$ significantly enhanced proliferation of MC3T3-E1 after $48 \mathrm{~h}(p<0.001)$, while $\mathrm{HfO}_{2}$ did not affect proliferation of pre-osteoclast cell line (Fig. 2a). Based on data obtained from repeated resazurin-based in vitro toxicology assay (TOX8), population doubling time (PDT)- the time required for a cell population to double their numberwas determined. The assay revealed that $\mathrm{HfO}_{2}$ significantly decreasedPDT value of pre-osteoblasts $(p<0.05)$, while did not change proliferation rate of $4 \mathrm{~B} 12$ (Fig. 2b).

To determine whether $\mathrm{HfO}_{2}$ affects cell apoptosis, the cells were cultured for $144 \mathrm{~h}$ ( 6 days) in normal condition or in the presence of $\mathrm{HfO}_{2}$. Relative expression of apoptosis-related genes was estimated using RT-qPCR. We detected that several genes expression was affected by $\mathrm{HfO}_{2}$ in both MC3T3-E1 and 4B12 cell lines. Exposition to $\mathrm{HfO}_{2}$ significantly increased expression of antiapoptotic $B C l 2$ (B cell lymphoma 2 gene) $(p<0.05)$ and downregulated pro-apoptotic $B A X$ (BCL2 associated $\mathrm{X}$ protein) $(p<0.05)$ that resulted in higher $B C l 2 / B A X$ ratio $(p<0.001)$ in MC3T3-E1 exposed to $\mathrm{HfO}_{2}$ indicating lower apoptosis rate (Fig. 3a). On the contrary, treatment with $\mathrm{HfO}_{2}$ evidently decreased mRNA level of antiapoptotic $B C l 2 \quad(p<0.05)$ caused low $B C l 2 / B A X$ ratio $(p<0.01)$. Interestingly, mRNA level of pro-apoptotic caspase 9 encoded by CASP9 $(p<0.001)$ and P53 (tumor protein p53) $(p<0.05)$ were significantly decreased in 4B12 after exposition to $\mathrm{HfO}_{2}$ compared to control group (Fig. 3b). Additionally, we noted that $\mathrm{HfO}_{2}$ markedly enhanced expression of miR-7a-5p $(p<0.001)$ and miR17-5p $(p<0.001)$ in MC3T3-E1, a widely known miRNA involved in promotion of cell proliferation and inhibition of apoptosis (Fig. 3c) [20, 21]. Conversely, those miRNAs are downregulated in 4B12 (Fig. 3d). To conclude, $\mathrm{HfO}_{2}$ upregulated BCL2/BAX ratio and expression of miR-7a-5p and miR-17-5p in MC3T3, while in 4B12 was observed inverse relation. In those cells, $\mathrm{HfO}_{2}$ diminished mRNA levels of CASP9 and P53, thus suggesting that $\mathrm{HfO}_{2}$ may inhibit cells apoptosis affecting different signaling pathways depending on cell type.

\section{$\mathrm{HfO}_{2}$ modulates expression of osteogenic and osteoclastogenic markers}

The effect of $\mathrm{HfO}_{2}$ on expression of specific markers involved in pre-osteoblast differentiation and bone formation after $144 \mathrm{~h}$ of culture was determined using RTqPCR technique and immunofluorescence staining. We observed overexpression of runt-related transcription factor $2(R U N X 2)(p<0.001)$ and transforming growth factor $\beta$ encoded by TGFB in MC3T3-E1 cells exposed to $\mathrm{HfO}_{2}$ (Fig. 4a). In addition, osteopontin $(O P N)(p<0.05)$ was upregulated, while osteocalcin encoded by $O C N$ $(p<0.05)$ was downregulated in $\mathrm{HfO}_{2}$ group (Fig. 4a). Additionally, $\mathrm{HfO}_{2}$ positively regulated expression of 
a

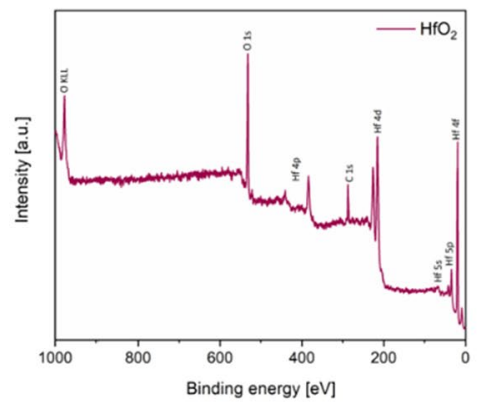

b

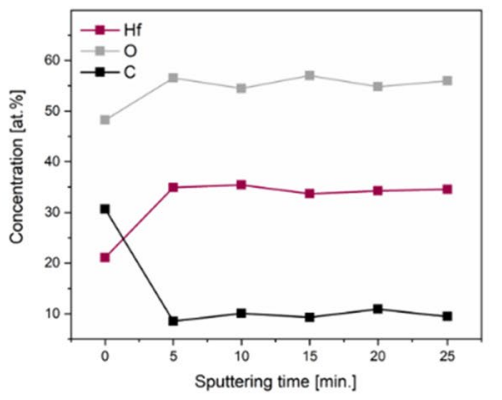

C

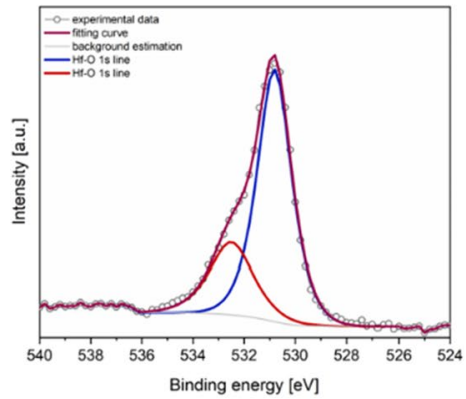

f

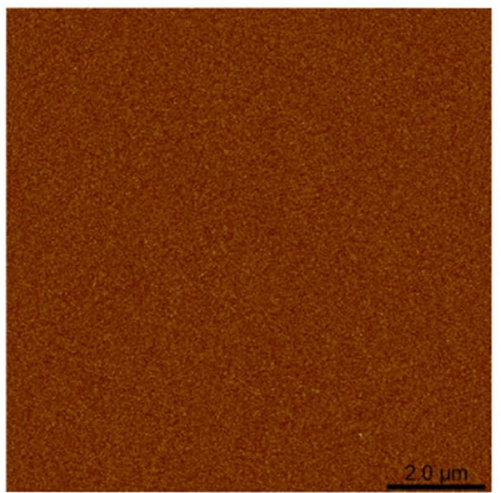

d



e

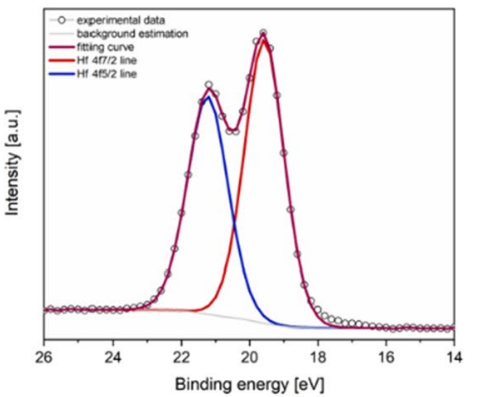

g

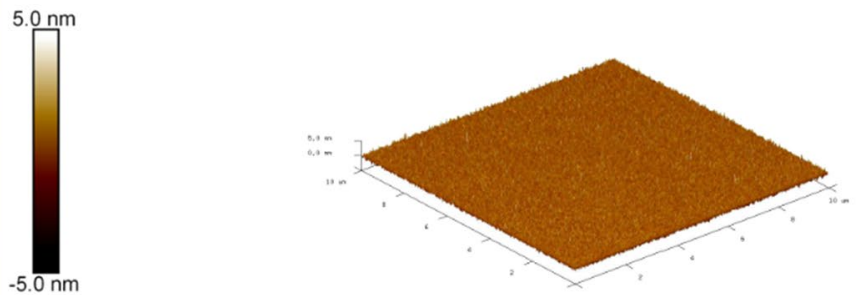

Fig. 1 Spectrum of XPS measured over a wide range of elements binding energy (a), only O, Hf and C were detected. The distribution of elements: $\mathrm{Hf}, \mathrm{O}$ and $\mathrm{C}$ as a function of $\mathrm{Ar}^{+}$spattering time (b), high resolution $\mathrm{O} 1 \mathrm{~s}$ line decomposed into two components: bonded with $\mathrm{Hf}$ (blue line) and atmospheric contamination (red line) (c), hafnium $4 f 7 / 2$ (red line) and $4 f 5 / 2$ (blue line) spin -orbit doublet before sputtering (d) and after sputtering (e), the second spin-orbit doublet should be added to account for $\mathrm{Hf}$ bonded with less than 7 oxygen atoms. The AFM images of obtained $\mathrm{HfO}_{2}$ thin layer: top view of scan area equal to $4 \mu \mathrm{m}^{2}$ (f) and three-dimensional view of scan area of $100 \mu \mathrm{m}^{2}(\mathbf{g})$

two key miRNA involved in osteogenesis: miR-21-5p $(p<0.01)$ and miR-16-5p $(p<0.001)$ (Fig. 2b). miR-21-5p is widely known osteogenesis stimulator, whereas miR16 suppress expression of key osteogenic markers and mineral calcium deposition by mesenchymal stem cells during osteogenic differentiation [22, 23]. Immunofluorescence staining revealed significant differences in distribution of RUNX2 and osteoprotegerin (OPG), as well as substantial alternation in the expression of OPN between experimental groups. In normal culture condition, RUNX2 exhibited perinuclear localization in MC3T3-E1, while $\mathrm{HfO}_{2}$ induced subcellular distribution of this protein (Fig. 4c). Similarly, exposition to $\mathrm{HfO}_{2}$ caused shift in fluorescence from nucleus area to cytoplasm of OPG (Fig. 4d). It is also worth noting that $\mathrm{HfO}_{2}$ increased expression of OPN protein (Fig. 4d).

RT-qPCR results revealed that after $144 \mathrm{~h}$ of culture, $\mathrm{HfO}_{2}$ negatively regulated expression of genes involved 
in osteoclastogenesis. We observed significant decline in expression of $c . F O S(p<0.001)$, PU.1 $(p<0.001)$, RANK (receptor activator of nuclear factor $\mathrm{k} \mathrm{B})(p<0.001)$ and TRAP (tartrate-resistant acid phosphatase), whereas upregulation of calcitonin receptor isoform 1a encoded by CR1A $(p<0.01)$ in $\mathrm{HfO}_{2}$ group (Fig. 5). These data indicated that $\mathrm{HfO}_{2}$ induces overexpression of osteoblastogenic markers, affects the content of OPN, as well as distribution profile of RUNX and OPG, while inhibits expression of genes crucial for pre-osteoclast differentiation.

\section{Biocompatibility analysis of $\mathrm{HfO}_{2}$ on RAW 264.7 cells}

Biocompatibility of $\mathrm{HfO}_{2}$ was evaluated using macrophage cell line RAW 264.7. Cells were seeded on standard glass slides or glass slides coated with $\mathrm{HfO}_{2}$ and allowed to attach overnight. Next, cells were exposed to lipopolysaccharide (LPS) for another 4 and $24 \mathrm{~h}$. Cells treated with LPS $(1 \mu \mathrm{g} / \mathrm{mL})$ served as positive control for macrophage activation. F-actin staining revealed multiple morphological alternations in LPS positive groups after only a $4 \mathrm{~h}$ of treatment. When RAW 264.7 were exposed for $4 \mathrm{~h}$, pseudopodia were formed and extended from few sides of cells (Fig. 6a). Pseudopodia were further extended after $24 \mathrm{~h}$ of LPS-stimulated macrophages (indicated with white arrows), whereas treatment with $\mathrm{HfO}_{2}$ diminished those LPS-induced morphological changes (Fig. 6b). Interestingly, we observed significant increase in cell size of macrophages induced with LPS after $24 \mathrm{~h}$ of exposition. In addition, co-treatment of $\mathrm{HfO}_{2}$ and LPS reversed LPS-induced alternations. Those cells displayed spherical shape and smooth surface similarly to negative control (RAW cultured in standard condition).

In the second step of the experiment polarization of macrophage M1/M2 using RT-qPCR method was investigated. We noted that LPS-treated macrophages exhibited overexpression of cytokines involved in M1 polarization, such as nitric oxide synthase (INOS), tumor necrosis factor alpha (TNFA), interleukin 6 (IL6) and interleukin (IL1B) after $4 \mathrm{~h}$ of LPS stimulation (Fig. 7a). Interestingly, $\mathrm{HfO}_{2}$ significantly increased expression of anti-inflammatory interleukin 10 (IL10) $(p<0.05)$ (Fig. 7b) after $4 \mathrm{~h}$ of treatment.




Expression of INOS, TNFA, IL6 and IL1B was increased while IL6 decreased after $24 \mathrm{~h}(p<0.001)$ of exposition with LPS (Fig. 7c). No statistically significant differences were noted in the expression of IL10, IL4 and TGFB after
$24 \mathrm{~h}$ of LPS stimulation (Fig. 7d). In addition, $\mathrm{HfO}_{2}$ alone did not affect macrophages activation suggesting its biocompatibility. The obtained results indicate on antiinflammatory properties of $\mathrm{HfO}_{2}$.
MC3T3-E1

a

CASP9

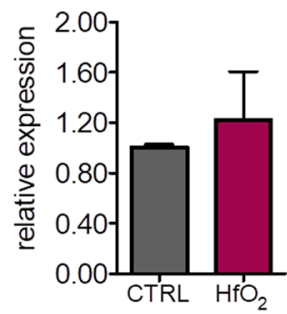

$B C / 2$

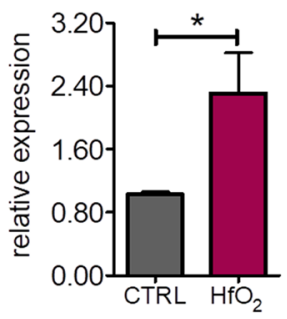

P53

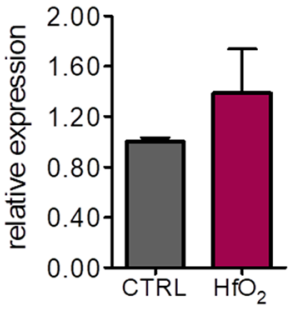

$B A X$



b

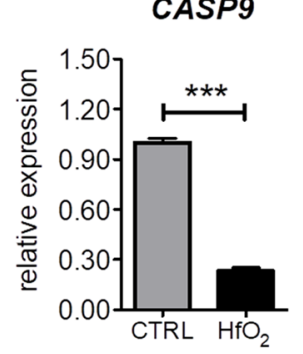

$B C / 2$

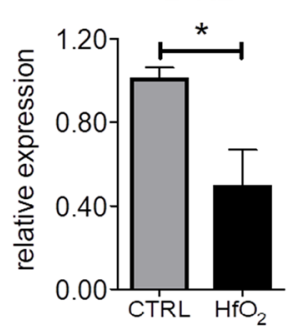

4B12
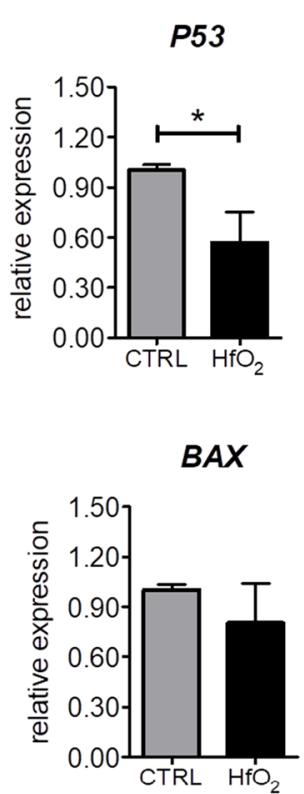

$B C / 2 / B A X$
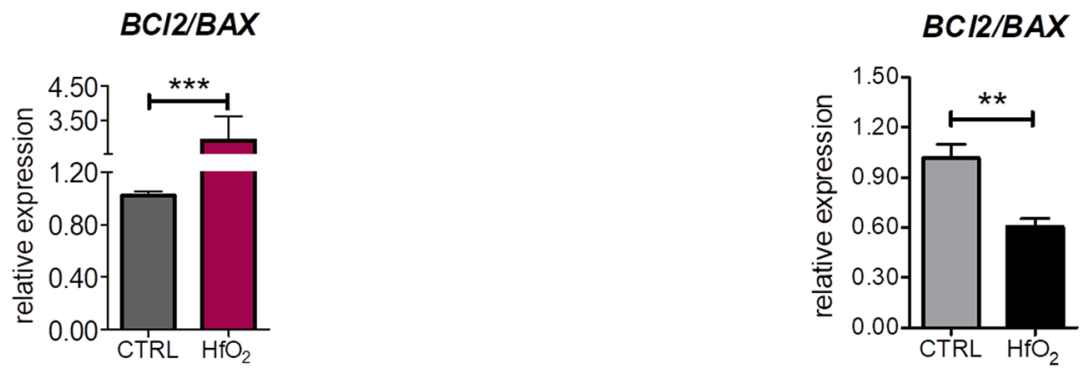

c

miR-7a-5p

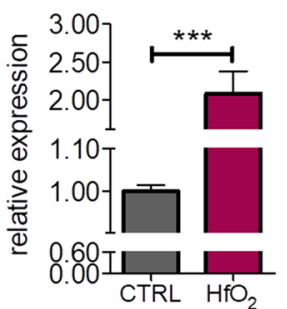

miR-17-5p

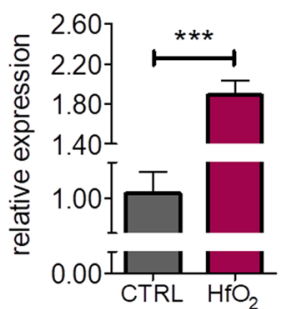

miR-7a-5p

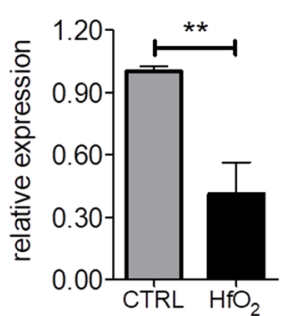

$\operatorname{miR}-17-5 p$

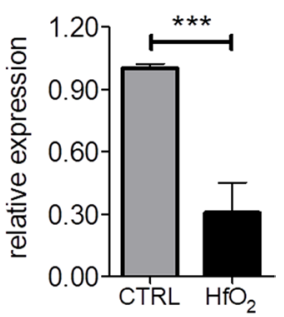

Fig. 3 The effect of $\mathrm{HfO}_{2}$ on the expression of apoptosis-related genes and miRNAs in MC3T3-E1 and 4B12 cells after $144 \mathrm{~h}$ of culture. Expression pattern of CASP9, P53, BCl2 and BAX was determined using RT-qPCR method (A-B). BCL2/BAX ratio was calculated based on relative expression of those genes. GAPDH was used as housekeeping gene. The relative level of miR-7a and miR-17-5p was estimated with Mir-X-system using RT-qPCR method (C-D). U6 was used as normalization control. Error bars represent the means \pm SD. ${ }^{*} p<0.05,{ }^{* *} p<0.01,{ }^{* * *} p<0.001$; Student's $t$ test 


\section{Discussion}

In presented paper we described a deposition of a smooth amorphous layers of $\mathrm{HfO}_{2}$ using the ALD process and its characterization studies with XRD and AFM. It is well known that, the selection of the ALD parameters determines the surface structure. The temperature and the number of cycles are most crucial parameters affecting ALD [11]. The layers obtained in the low-temperature ALD process are amorphous, which in turn ensures perfect adhesion to the substrate [24]. On the other hand, appropriate selection of ALD cycles determines the thickness of the layer. As we have shown in our previous research, hafnium (IV) oxide coatings tend to crystallize during deposition of the thicker layers and at increased process temperature [24]. Considering the specific growth rate $(1.9 \AA /$ cycle) for the selected process at the temperature of $90^{\circ} \mathrm{C}$, here we performed the $100 \mathrm{~nm}$ deposition process, which was confirmed by measuring film thickness using reflectometry. The characteristic feature of ALD is thickness adjustment of the films by determining the number of full ALD cycles in relation to the growth rate under given thermodynamic conditions [9].

Strong adhesion of the amorphous layer with the substrate will guarantee its strength in conditions of mechanical load to which hard tissue implants are subjected. Among the high material requirements for implant coatings a lack of cracks, both on the surface and on the interface of the materials, should be considered. Damage on the interfaces weakens the mechanical properties of the coating and, propagating towards the surface, can cause separation of micro fragments of the layer, which will lead to destruction of the coating during use of the implant.

XPS analysis of the chemical composition showed an excess of oxygen on the surface. About $25 \%$ of the oxygen was associated with surface pollution, clearly more than stoichiometric value for $\mathrm{HfO}_{2}$. This indicate on hydrophilic nature of the substrate, which significantly improves the biological properties of the surface [25]. Ultimately, the ratio of oxygen to hafnium is 1.86 , which is close to the ideal stoichiometry. The lower ratio of $\mathrm{O}$ to $\mathrm{Hf}$ during sputtering results from the fact that $2 \mathrm{keV} \mathrm{Ar}$ ions preferentially remove $\mathrm{O}$ from the surface. Nevertheless, XPS depth profiling confirmed the homogeneity of the formed film.

Although the $\mathrm{HfO}_{2}$ layer is a widely studied material by many research groups $[26,27]$, its application in regenerative medicine is a new approach. In our previous research we have showed that $\mathrm{HfO}_{2}$ films obtained by ALD technology are characterized by high cyto-compatibility and antimicrobial properties $[28,29]$,. In the present study, we investigated whether $\mathrm{HfO}_{2}$ layers are able to modulate metabolic activity of both osteoblasts and osteoclasts and thus may be utilized in the fabrication of implants used in the fixation of osteoporotic bone fractures. Since now, limited number of studies regarding biological properties of hafnium oxide have been performed and none of them related to bone remodeling. A study performed by Fohlerova and Mozalev revealed that hafnium-oxide thin films on substrates via self-organized electrochemical anodization were characterized by good cytocompatibility (tested with MG-63 osteoblastlike cells) and anti-microbial properties (tested with Gram-negative E. coli bacteria) [30]. It was also shown that hafnium oxide nanoparticles can induce DNA damage and apoptosis in human colorectal cancer cells [31]. Cytotoxicity of hafnium oxide nanoparticles was also tested by Field et al. [32]. who revealed that these particles are relatively non-toxic in human $\mathrm{HaCaT}$ skin cells. Here we observed, that $\mathrm{HfO}_{2}$ promotes pre-osteoblasts, while inhibits pre-osteoclasts viability. What is more important, $\mathrm{HfO}_{2}$ protects pre-osteoblast against apoptosis through enhanced expression of BCL-2 transcript and at the same time induces pre-osteoclasts apoptosis. Obtained data delivers interesting scientific findings which can be utilized as a strategy in the course of osteoporotic bone regeneration via silencing osteoclasts overactivity [33]. Interestingly, we observed, that $\mathrm{HfO}_{2}$ protects pre-osteoblasts against apoptosis not only by activation particular osteogenesis related genes but also by induction of miR-17-5p and miR-7a-5p expressioncrucial regulators of osteoblasts proliferation activity as well as inhibition of apoptosis $[34,35]$. For that reason, we speculate that that the application of $\mathrm{HfO}_{2}$ on the surface of implantable metallic materials might become an effective anti-apoptotic strategy for osteoblast protection and at the same time enhance regenerative potential.

Restoring the balance between bone formation and bone resorption processes during OP is thought to be the most effective approach to prevent fractures and improve tissue homeostasis [36]. In the present study, we have found, that $\mathrm{HfO}_{2}$ promotes expression of runt-related transcription factor 2 (RUNX2), transforming growth factor $\beta$ encoded by TGFB and osteopontin (OPN) in osteoblasts on the both mRNA as well as protein level. In numerous studies, RUNX2 has been shown to participate in osteoblast growth and differentiation by triggering the expression of subsequent biomarkers of mature osteoblasts [36-39]. Moreover, RUNX2 is up-regulated in early stages of osteoblast differentiation, then downregulated in mature osteoblasts [40].

Obtained results indicated on beneficial effect of $\mathrm{HfO}_{2}$ in the context of the osteogenesis initiation. Moreover, we have demonstrated, that pre-osteoblasts exposed for $\mathrm{HfO}_{2}$ are characterized by enhanced expression of miR21-5p and miR-16-5p- two critical transcripts involved 


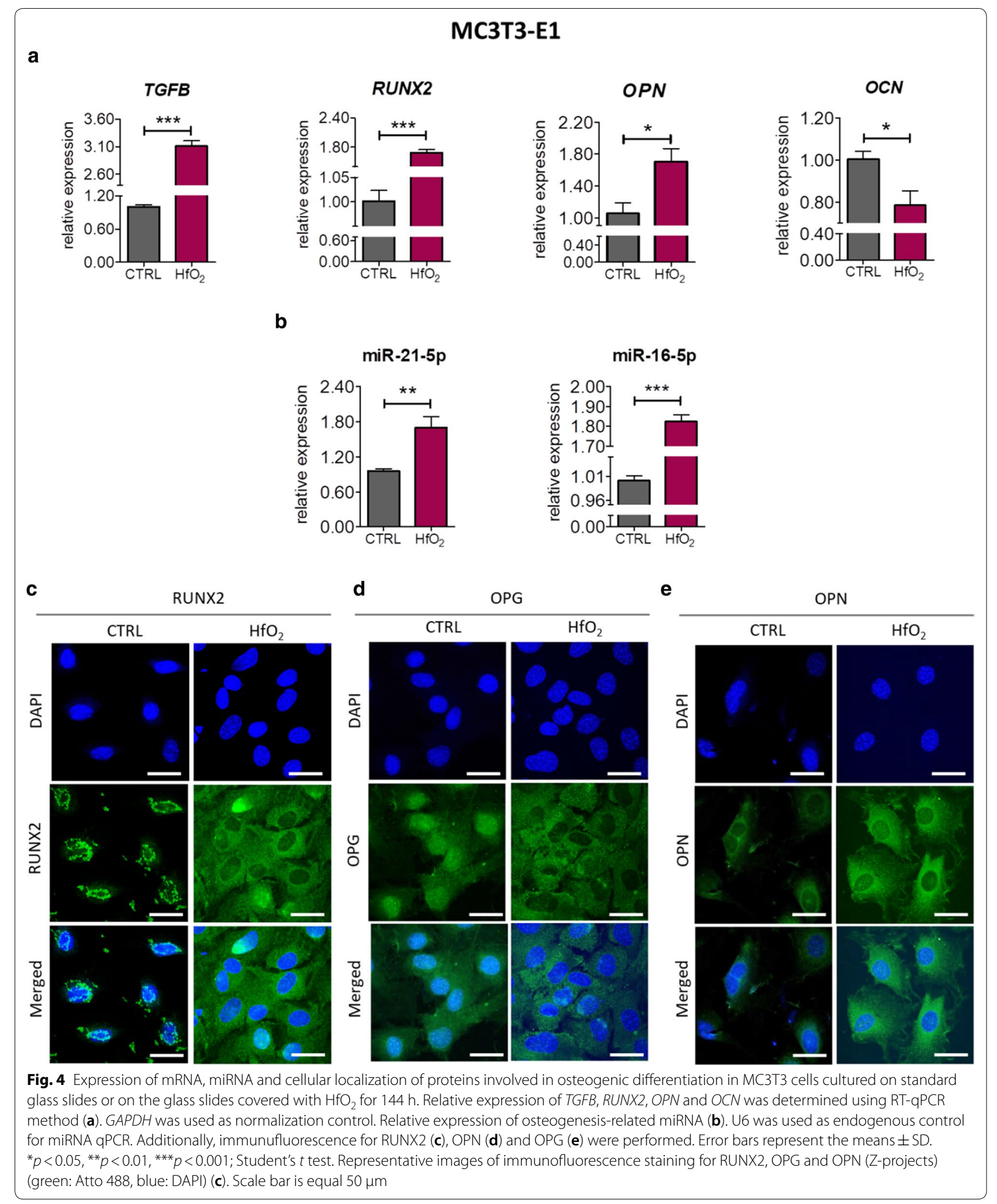




\section{B12}

c.FOS

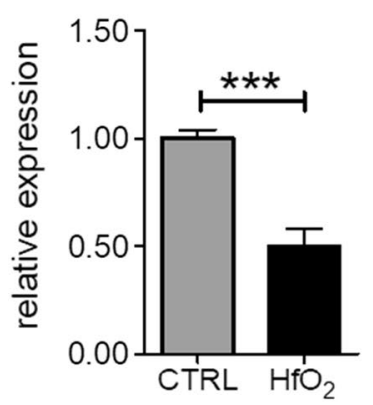

RANK



MMP9

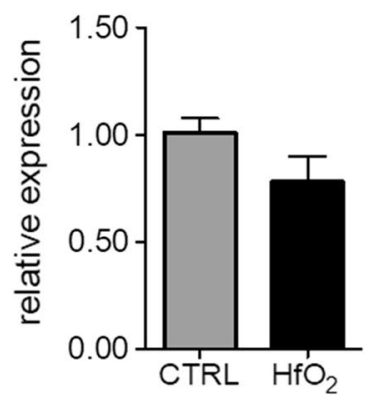

TRAP

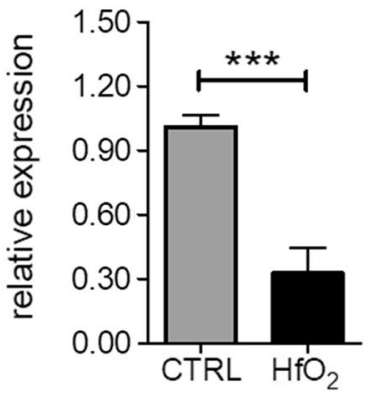

PU.1

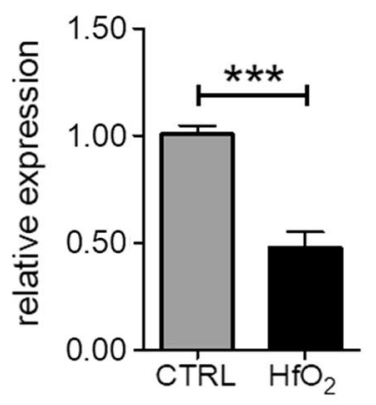

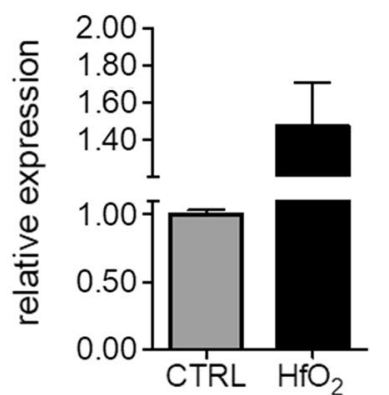

Fig. 5 Expression of osteoclast-specific genes in 4B12 cells after $144 \mathrm{~h}$ of culture in normal condition or in the presence of $\mathrm{HfO}_{2}$. $\mathrm{mRNA}$ level of C.FOS, MMP9, PU.1, RANK, TRAP and CR1A was determined using RT-qPCR method. Gene expression data was normalized to the expression of GAPDH. Error bars represent the means $\pm \mathrm{SD} .{ }^{*} p<0.05,{ }^{* *} p<0.01,{ }^{* * *} p<0.001$; Student's $t$ test

in osteogenesis and bone mineralization. Interestingly, when compared to control cells, $\mathrm{HfO}_{2}$ did not promote osteocalcin expression, which mediates biomineralization during osteogenic maturation [41]. For that reason, we speculate that $\mathrm{HfO}_{2}$ might serve as an bioactive agent able to modulate and trigger osteoblastogenesis. On the other hand, we have shown that besides activation of osteogenesis, $\mathrm{HfO}_{2}$ inhibits osteoclastogenesis. We have shown, that $\mathrm{HfO}_{2}$ reduce the expression of key factors regulating osteoclasts differentiation- c.FOS, MMP9, PU.1, RANK and TRAP. Furthermore, It was also shown, that certain proinflammatory cytokines could induce osteoclastogenesis and can target osteoclasts via directly or via RANK/OPG axis [42]. Numerous studies indicated on systemic and local inflammation as an events negatively affecting bone remodeling supporting the theory regarding inflammation-related OP pathogenesis [43]. In the present study we have shown, that $\mathrm{HfO}_{2}$ exerts immunomodulatory effect, since it increased expression of anti-inflammatory IL10 in LPS-treated macrophages propagated onto $\mathrm{HfO}_{2}$. Moreover, we noted significantly reduced expression of IL-6 which is common cytokine characteristic for osteoporosis [44]. Obtained results strongly suggests, that $\mathrm{HfO}_{2}$ exerts anti-inflammatory effect, which might become an important factor, when its application in future implantology is considered.

\section{Conclusions}

Recently, there is an urgent need to develop a smart, bioactive materials for OP bone regeneration that would be able to modulate osteoblasts-osteoclasts axis in order to improve fracture healing. In the present study, using ADL technology we obtained homogeneous, amorphous layer of $\mathrm{HfO}_{2}$ which exerted anti-apoptotic and pro-osteogenic effects in vitro. We have shown, that $\mathrm{HfO} 2$ promotes osteogenic differentiation through the activation of early markers of osteogenesis while inhibits viability and maturation of osteoclasts. Furthermore, $\mathrm{HfO} 2$ was characterized by immunomodulatory effects which shed a promising light for its future application as an active layer for covering metallic materials. 


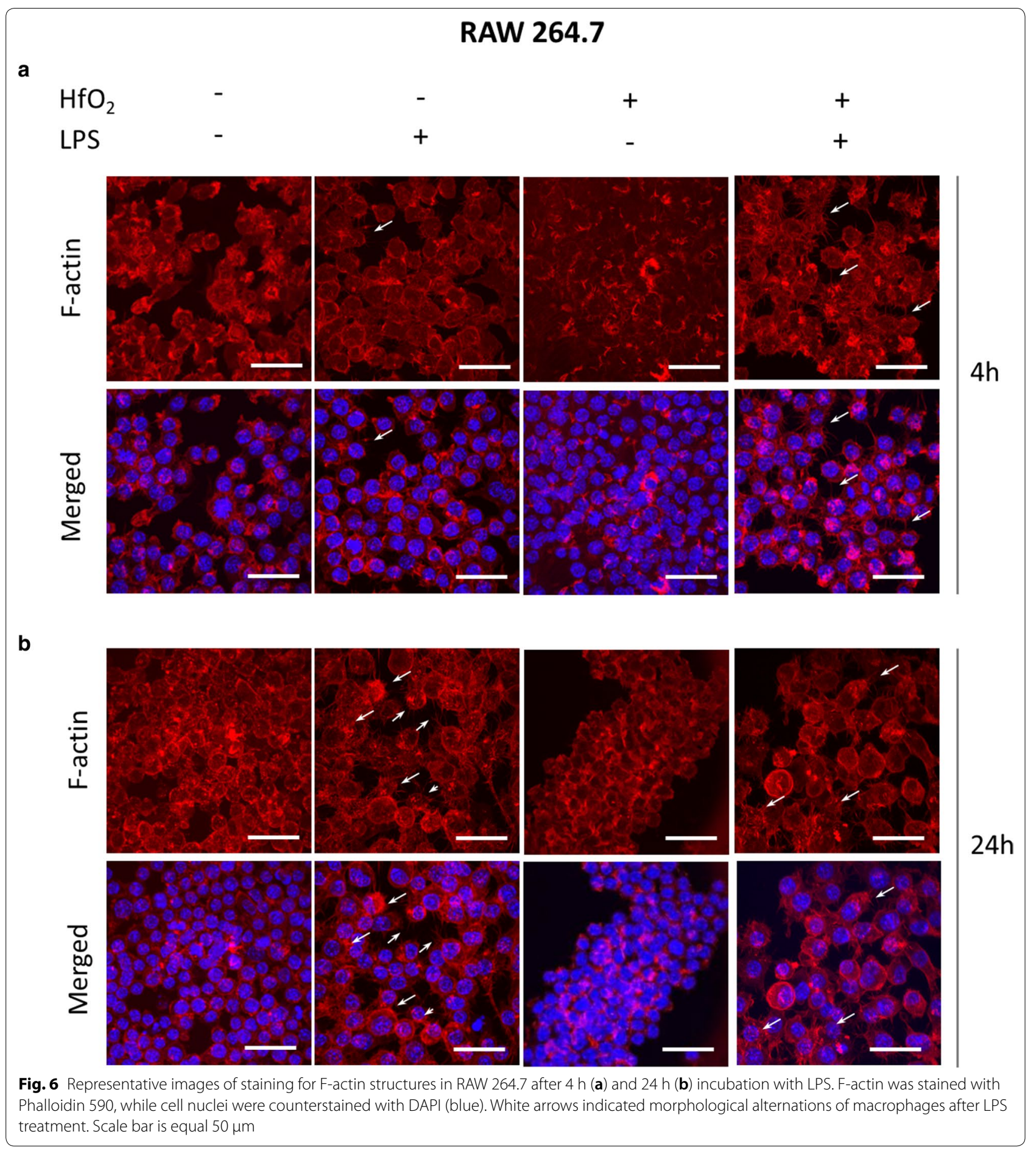

\section{Methods}

\section{Substrate preparation}

The $\mathrm{HfO}_{2}$ layers were deposited on $10 \mathrm{~mm} \times 10 \mathrm{~mm}$ silicon plates for physicochemical evaluations and on glass cover slips with a diameter of $12 \mathrm{~mm}$ for biological evaluation. Superficial contaminants may affect the adherence of the ALD films to the substrate and negatively affect the homogeneity of the layer. Thus, we have prepared the substrates by three washing cycles before the deposition process. The first bath was carried out in isopropanol, the next two in deionized water. All of them were performed 
a


\section{b}

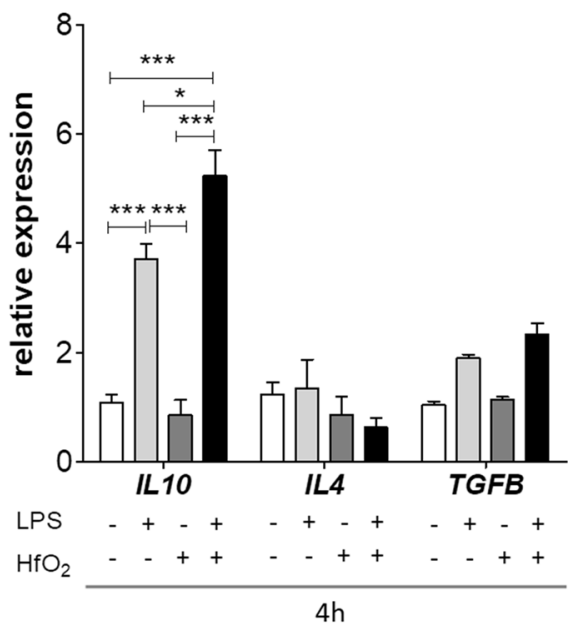

d

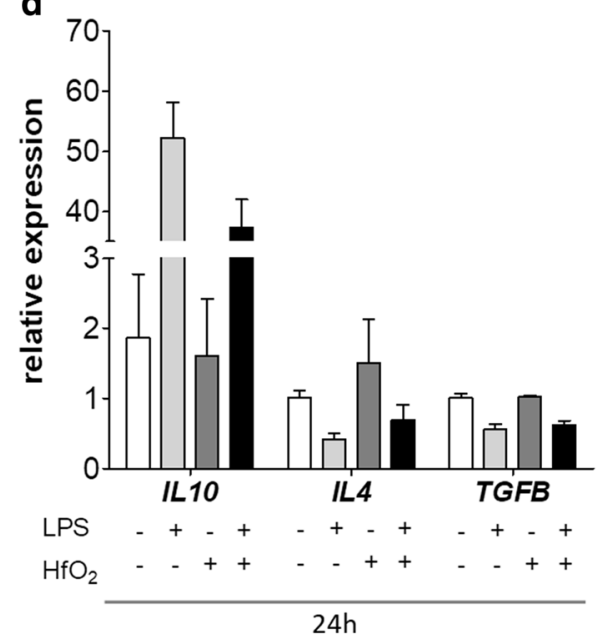

Fig. 7 Changes in the expression of pro- and anti-inflammatory cytokines. Relative expression of cytokines was assessed after $4 \mathrm{~h}(\mathbf{a}, \mathbf{b})$ and $24 \mathrm{~h}(\mathbf{c}$, d) stimulation with LPS using RT-qPCR method. GAPDH was used as housekeeping gene. Error bars represent the means \pm SD. ${ }^{*} p<0.05$, ${ }^{* *} p<0.01$, ${ }^{* * *} p<0.001$; Two-way ANOVA analysis of variance followed by Bonferroni post hoc testes

in the ultrasound cleaner with bath in $37^{\circ} \mathrm{C}$. Afterwards all substrates were dried in nitrogen of $5 \mathrm{~N}$ purity.

\section{ALD technology}

A Savannah-100 Cambridge NanoTech ALD reactor was used to perform the deposition of $\mathrm{HfO}_{2}$ films. We selected Tetrakis(dimethylamido)hafnium (TDMA-Hf, $\mathrm{Hf}\left[\left(\mathrm{CH}_{3}\right)_{2} \mathrm{~N}\right]_{4}$, CAS number 19782-68-4) as the metal precursor and deionized water as the oxygen precursor. Forming of $\mathrm{HfO}_{2}$ occurs through a double exchange reaction [45]:

$$
\mathrm{Hf}\left[\left(\mathrm{CH}_{3}\right)_{2} \mathrm{~N}\right]_{4}+2 \mathrm{H}_{2} \mathrm{O}->\mathrm{HfO}_{2}+4 \mathrm{HN}\left(\mathrm{CH}_{3}\right)_{2} .
$$

Precursors cycles were introduced sequentially into the growth chamber separated by purge phase of a growth chamber with nitrogen $(6 \mathrm{~N})$. The pulse times were equal $0.2 \mathrm{~s}$ and $0.04 \mathrm{~s}$ for hafnium precursor and for oxidant precursor respectively, with purge times equal $8 \mathrm{~s}$ after hafnium precursor doses and $22 \mathrm{~s}$ after oxygen precursor doses. The growth process of $\mathrm{HfO}_{2}$ consisted of 519 ALD cycles. The creation of films was carried out in the temperature $90{ }^{\circ} \mathrm{C}$ and vacuum below $66 \mathrm{~Pa}$. At such process parameters the deposition rate was equal to $1.9 \AA$ per one ALD cycle. 
Tests equipment for physicochemical analysis

To determine the thickness of the layer a NanoCalc 2000-UV/VIS (Micropack GmbH) system with specific software was used. The layer thickness was measured on a silicon substrate. The reflection spectrum from the silicon substrate without the layer was used as a reference measurement.

The crystallinity of the coatings was checked by XRD investigations. A Panalytical X'Pert Pro MRD diffractometer was used, equipped with an X-ray tube generating radiation at a wavelength of $1.54056 \AA$, a hybrid twobounce Ge (220) monochromator, and a Pixcel detector.

A Scienta R4000 hemispherical analyzer (with pass energy $200 \mathrm{eV}$ ) and non-monochromatic $\mathrm{Al} \mathrm{K \alpha}$ emission line with excitation energy equal to $1486.6 \mathrm{eV}$, was used for XPS measurements. At those experimental setting, the measured full width at half maximum of the $\mathrm{Au} 4 \mathrm{f} 7 / 2$ line was $1.1 \mathrm{eV}$. The carbon (C) $1 \mathrm{~s}$ line was bonded with the energy $285 \mathrm{eV}$ and used to calibrate the energy scale. The neutralization gun was applied to avoid meaningful sample charging. A notable amount of carbon was found in as received sample. The depth profiling with $2 \mathrm{kV} \mathrm{Ar}$ ion gun was performed to test if the carbon was immanent at the surface only and to check the film homogeneity. The spectra were analysed using CASA program (Casa Software Ltd version 2.3.17).

Surface morphology was examined using the AFM Dimension Icon from Bruker. The equipment was operated in the PeakForce Tapping mode using silicon nitride SCANASYST-AIR probe with tip radius of $2 \mathrm{~nm}$. The applied mode of operation allows imaging of the surface based directly on interaction forces between the probe and the sample. In addition, the ScanAsyst algorithm was used for the measurements. It allows continuous monitoring the image quality and automatic optimization of the selected parameters (ScanAsyst Auto Gain and ScanAsyst Auto Setpoint) according to sample condition during scanning. Measurements were performed in air under ambient conditions with a scan rate of $0.70 \mathrm{~Hz}$. Each area was scanned with $512 \times 512$ pixels resolution. AFM data analysis was made with NanoScope Analysis software.

\section{In vitro cell culture}

Murine MC3T3-E1 pre-osteoblasts were cultured in Minimum Essential Media Alpha without ascorbic acid (MEM- $\alpha$, Gibco $^{\text {TM }}$ Thermo Fisher Scientific, MA, USA) supplemented with $10 \%$ feta bovine serum (FBS, Sigma Aldrich, Munich, Germany). The murine osteoclast precursor cell line 4B12 was kindly provided by Shigeru Amano from Department of Oral Biology and Tissue Engineering, Meikai University School of Dentistry [46]. The $4 \mathrm{~B} 12$ cells were propagated in complete growth medium consisting of $\alpha$-MEM (Sigma Aldrich, Munich, Germany) supplemented with $30 \%$ of calvaria-derived stromal cell conditioned medium (CSCM) and 10\% FBS. Murine macrophage cell line RAW 264.7 was cultured in complete growth medium consisted of Dulbecco's Modified Eagle Medium (DMEM, Sigma Aldrich, Munich, Germany) with $500 \mathrm{mg} / \mathrm{L}$ glucose supplemented with $10 \%$ FBS. Cells were cultivated in the $\mathrm{CO}_{2}$ incubator at constant conditions $\left(37{ }^{\circ} \mathrm{C}, 5 \% \mathrm{CO}_{2}\right.$, and $95 \%$ humidity). Medium was refreshed every 2-3 days. The cells were passaged when population reached $80 \%$ confluence using recombinant cell-dissociation enzyme StableCell Trypsin (Sigma Aldrich, Munich, Germany) or by gentle scrapping and pipetting (4B12).

\section{Cell proliferation assay}

Cell proliferation rate was estimated using a resazurinbased assay kit (TOX8) (Sigma Aldrich, Munich, Germany) in accordance to manufacturer's protocol [47]. For the assay MC3T3-E1 and 4B12 cells were seeded in 24-well plates on regular glass slides (control group) or on glass slides coated with $\mathrm{HfO}_{2}$ at a density of $2 \cdot 10^{4}$ cell/ well. The test was performed at 48,72 and $144 \mathrm{~h}$ of experiment. Briefly, culture media was replaced with fresh media supplemented with $10 \% \mathrm{v} / \mathrm{v}$ resazurin dye, and incubation was carried out for $2 \mathrm{~h}$ at $37{ }^{\circ} \mathrm{C}$ in the $\mathrm{CO}_{2}$ cell culture incubator (Thermo Fisher Scientific, MA, USA). Then, supernatants were transferred to 96-well plate in the volume of $100 \mu \mathrm{l}$ per well and measured spectrophotometrically at a wavelength of $600 \mathrm{~nm}$ and $690 \mathrm{~nm}$ reference length (Epoch, Biotek, Germany) Population doubling time (PDT) was calculated using an algorithm available on-line [48].

\section{Macrophage activation}

RAW 264.7 cells were seeded in 24-well plate on regular glass slides (control) or on glass slides coated with $\mathrm{HfO}_{2}$ a density of $3 \cdot 10^{5}$ cells/well. After $24 \mathrm{~h}$ lipopolysaccharide (LPS, $1 \mu \mathrm{g} / \mathrm{mL}$, Sigma Aldrich, Munich, Germany) was added to culture media for another 4 and $24 \mathrm{~h}$. Macrophage activation was analyzed using RT-qPCR technique and confocal microscopy.

\section{Confocal microscopy}

Cellular distribution and expression of runt-related transcription factor 2 (RUNX2), osteoprotegerin (OPG), and osteopontin (OPN) in MC3T3-E1 cells were determined using immunofluorescence [49]. Cells were cultivated for 6 days on glass slides with and without $\mathrm{HfO}_{2}$ layer (control group). First, cells were fixed with $4 \%$ paraformaldehyde (PFA) for $30 \mathrm{~min}$ at room temperature, washed three times with Phosphate Buffered Saline (PBS, Sigma Aldrich, Munich, Germany), and then incubated with 
Table 1 Sequence of primers used for mRNA expression analysis using RT-qPCR method

\begin{tabular}{|c|c|c|c|c|}
\hline Gene abbreviation & Gene full name & Sequence of primer $\left(5^{\prime} \rightarrow 3^{\prime}\right)$ & $\begin{array}{l}\text { Amplicon } \\
\text { lenght }\end{array}$ & Accession No. \\
\hline \multirow[t]{2}{*}{ CASP9 } & Caspase-9 & F: CCGGTGGACATTGGTTCTGG & 278 & NM_001355176.1 \\
\hline & & R: GCCATCTCCATCAAAGCCGT & & \\
\hline \multirow[t]{2}{*}{ P53 } & p53 tumor suppressor & F: AGTCACAGCACATGACGGAGG & 287 & XM_030245924.1 \\
\hline & & R: GGAGTCTTCCAGTGTGATGATGG & & \\
\hline \multirow[t]{2}{*}{$B C 12$} & B-cell lymphoma 2 & F: GGATCCAGGATAACGGAGGC & 141 & NM_009741.5 \\
\hline & & R: ATGCACCCAGAGTGATGCAG & & \\
\hline \multirow[t]{2}{*}{$B A X$} & Bcl-2-like protein 4 & F: AGGACGCATCCACCAAGAAGC & 251 & XM_011250780.3 \\
\hline & & R: GGTTCTGATCAGCTCGGGCA & & \\
\hline \multirow[t]{2}{*}{ TGFB } & Transforming growth factor beta 1 & F: GGAGAGCCCTGGATACCAAC & 94 & NM_011577.2 \\
\hline & & R: CAACCCAGGTCCTTCCTAAA & & \\
\hline \multirow[t]{2}{*}{ RUNX2 } & Runt-related transcription factor 2 & F:TCCGAAATGCCTCTGCTGTT & 130 & NM_001271630.1 \\
\hline & & R: GCCACTTGGGGAGGATTTGT & & \\
\hline \multirow[t]{2}{*}{ OPN } & Osteopontin & F: AGACCATGCAGAGAGCGAG & 340 & NM_001204203.1 \\
\hline & & R: GCCCTTTCCGTTGTTGTCCT & & \\
\hline \multirow[t]{2}{*}{ OCN } & Osteocalcin & F: GGTGCAGACCTAGCAGACACCA & 100 & NM_001032298.3 \\
\hline & & R: CGCTGGGCTTGGCATCTGTAA & & \\
\hline \multirow[t]{2}{*}{ c.FOS } & c-fos proto-oncogene & F: CCAGTCAAGAGCATCAGCAA & 248 & NM_010234.3 \\
\hline & & R:TAAGTAGTGCAGCCCGGAGT & & \\
\hline \multirow[t]{2}{*}{ MMP9 } & Matrix metallopeptidase 9 & F:TTGCCCCTACTGGAAGGTATTAT & 172 & XM_006498861.3 \\
\hline & & R: GAGAATCTCTGAGCAATCCTTGA & & \\
\hline \multirow[t]{2}{*}{ PU.1 } & Transcription factor PU.1 & F: GAGAAGCTGATGGCTTGGAG & 175 & XM_017316733.2 \\
\hline & & R:TTGTGCTTGGACGAGAACTG & & \\
\hline \multirow[t]{2}{*}{ RANK } & Receptor activator of nuclear factor $\mathrm{k} B$ & F:TTAAGCCAGTGCTTCACGGG & 473 & NM_009399.3 \\
\hline & & R: ACGTAGACCACGATGATGTCGC & & \\
\hline \multirow[t]{2}{*}{ TRAP } & Tartrate-resistant acid phosphatase & F: GTCTCTGGGGGACAATTTCTACT & 241 & XM_006509945.3 \\
\hline & & R: GTTTGTACGTGGAATTTTGAAGC & & \\
\hline \multirow[t]{2}{*}{ CR1A } & Calcitonin receptor isoform 1a & F:TGCGGCGGGATCCTATAA & 238 & NM_001355192.1 \\
\hline & & R: AGCCAGCAGTTGTCGTTGTA & & \\
\hline \multirow[t]{2}{*}{ INOS } & Nitric oxide synthase & F: GACAAGCTGCATGTGACATC & 325 & NM_001313922.1 \\
\hline & & R: GCTGGTAGGTTCCTGTTGTT & & \\
\hline \multirow[t]{2}{*}{ TNFA } & Tumor necrosis factor a & F: ACAGAAAGCATGATCCGCGA & 295 & NM_013693.3 \\
\hline & & R: CTTGGTGGTTTGCTACGACG & & \\
\hline \multirow[t]{2}{*}{ IL6 } & Interleukin 6 & F:GAGGATACCACTCCCAACAGACC & 141 & NM_001314054.1 \\
\hline & & R:AAGTGCATCATCGTTGTTCATACA & & \\
\hline \multirow[t]{2}{*}{$\operatorname{ILIB}$} & Interleukin 1 beta & F:TGCCACCTTTTGACAGTGATG & 138 & NM_008361.4 \\
\hline & & R:TGATGTGCTGCTGCGAGATT & & \\
\hline \multirow[t]{2}{*}{$\angle 10$} & Interleukin 10 & F: ATTTGAATTCCCTGGGTGAGAAG & 75 & NM_010548.2 \\
\hline & & R: CACAGGGGAGAAATCGATGACA & & \\
\hline \multirow[t]{2}{*}{ IL4 } & Interleukin 4 & F: GAATGTACCAGGAGCCATAT & 385 & NM_021283.2 \\
\hline & & R: CTCAGTACTACGAGTAATCCA & & \\
\hline \multirow[t]{2}{*}{ GAPDH } & Glyceraldehyde 3-phosphate dehydrogenase & F:TGCACCACCAACTGCTTAG & 177 & XM_017321385.2 \\
\hline & & R: GGATGCAGGGATGATGTTC & & \\
\hline
\end{tabular}

0.2\% Tween 20 (Sigma Aldrich, Munich, Germany) solution in PBS for another $15 \mathrm{~min}$. Then, samples were blocked with 5\% goat serum (Sigma Aldrich, Munich, Germany) for $1 \mathrm{~h}$ and incubated with primary antibodies at $4{ }^{\circ} \mathrm{C}$ overnight. The following antibodies were used:
OPN (dilution 1:1000 in PBS, ab8448, Abcam, Cambridge, UK), OPG (dilution 1:50 in PBS, sc-390518, Santa Cruz Biotechnology, Dallas, TX, USA), RUNX2 (dilution 1:50 in PBS, sc-390351, Santa Cruz Biotechnology, Dallas, TX, USA). After the primary antibody incubation, 
cells were rinsed three times with PBS and incubated with secondary antibodies conjugated with Alexa Fluor 488 (room temperature, $1 \mathrm{~h}$ ). Finally, cells were fixed on slides and nuclei were counterstained using mounting medium with DAPI (4,6-diamidino-2-phenylindole) (ProLong $^{\mathrm{TM}}$ Diamond Antifade Mountant with DAPI, Thermo Fisher Scientific, Warsaw, Poland). Cells were observed and imaged using confocal microscope (LEICA TSC SPE). Photos were analyzed with Image J software.

Changes in RAW 264.7 morphology after LPS-induced activation were estimated using F-actin staining. Prior staining, cells were fixed with $4 \%$ PFA after 4 and $24 \mathrm{~h}$ incubation with LPS and permeabilized using $0.2 \%$ Tween 20 as described above. Phalloidin Atto 590 was diluted in PBS (1:800, Sigma Aldrich, Munich, Germany) and added to cells for $40 \mathrm{~min}$. After three washing steps cells were mounted using ProLong ${ }^{\mathrm{TM}}$ Diamond Antifade Mountant with DAPI, observed and imaged using confocal microscope (LEICA TSC SPE).

\section{Reverse transcription quantitative polymerase chain reaction (RT-qPCR)}

Total RNA was isolated from MC3T3-E1 and 4B12 after 6 days of culture in normal condition or in the presence of $\mathrm{HfO}_{2}$, whereas total RNA extraction from RAW 264.7 was performed after 4 and $24 \mathrm{~h}$ of cultivation in normal condition or in the presence of HfO2 and/or LPS. RNA was isolated using phenol-chloroform method, as previously described by Chomczynski and Sacchi [50]. RNA quality and quantity were estimated spectrophotometrically at 260 and $280 \mathrm{~nm}$ wavelengths (Epoch, Biotek, Germany). thic.

Nawrocka et al. [51] for gene expression analysis, total RNA (150 ng per one reaction) was treated with DNase I using PrecisionDNAse kit (BLIRT S.A, Gdansk, Poland) followed by cDNA synthesis using RevertAidFirst Strand cDNA Synthesis Kit (Thermo Fisher Scientific, MA, USA). cDNA was subjected to real-time PCR with $5 \mu$ of SensiFast SYBR \& Fluorescein Kit (Bioline, UK), $1 \mu \mathrm{l}$ of cDNA and $500 \mathrm{nM}$ of each specific primer (see Table 1) in the total volume of $10 \mu \mathrm{l}$. All qPCR reactions were performed using CFX Connect ${ }^{\mathrm{TM}}$ Real-Time PCR Detection System (Bio-Rad, Hercules, CA, USA). Obtained data was normalized to the mean of GAPDH used as the housekeeping gene. The average fold change in the gene expression was analyzed using the $2^{-\Delta \Delta C T}$ method described by Livak and Schmittgen [52]. Furthermore, the expression ratio of $B C l 2 / B A X$ was determined by dividing the $\triangle \triangle \mathrm{CT}$ of those genes.

For miRNA expression analysis, $500 \mathrm{ng}$ of total cellular RNA was served for digestion of gDNA, as described above. RNA was polyadenylated and reverse transcribed
Table 2 Sequence of primers used for miRNA expression analysis using qPCR method

\begin{tabular}{lll}
\hline miRNA & Sequence of primer $\left(\mathbf{5}^{\prime} \boldsymbol{\rightarrow} \mathbf{3}^{\prime}\right)$ & Accession $\mathbf{N o}$. \\
\hline miR-7a-5p & TGGAAGACTAGTGATTTTGTTGT & MIMAT0000677 \\
miR-17-5p & CAAAGTGCTTACAGTGCAGGTAG & MIMAT0000070 \\
miR-21-5p & TAGCTTATCAGACTGATGTTGA & MIMAT0000530 \\
miR-16-5p & TAGCAGCACGTAAATATTGGCG & MIMAT0000069 \\
\hline
\end{tabular}

using the Mir-X miRNA First-Strand Synthesis Kit (Takara Bio, Japan) according to the manufacturer's protocol. Each qPCR reaction was performed in a total reaction mixture volume of $25 \mu \mathrm{l}$. Expression data were normalized using the $2^{-\triangle \Delta C T}$ method after normalization to the U6 snRNA used as a housekeeping gene. Sequence of the primers are listed in the Table 2.

\section{Statistical analysis}

All experiments included at least three technical repetitions. Comparison between two groups were analyzed using two-tailed Student's $t$ test. Differences among more than two groups were analyzed using two-way ANOVA analysis of variance followed by Bonferroni post hoc testes. Values of $p<0.05$ were considered statistically significant. All data are means \pm SD.

\section{Acknowledgements \\ 4B12 cell line was kindly provided by Dr Shigeru Amano- Division of Microbiol- ogy and Immunology, Department of Oral Biology and Tissue Engineering, Meikai University School of Dentistry, Keyakidai, Sakado City, Saitama 350- 0283, Japan.}

\section{Authors' contributions}

AS, MG, KKG and KM designed the research. AS, MA, KLJ, MO, PK, MG performed the experiments and collected and analyzed the data. AS, MA, AF, KLJ, MO, PK and validated the results. AS, MG, KM, MG wrote the manuscript text and prepared the figures. KM, MG, KKG and AS have read critically and edited the manuscript. KM acquired the funding. All authors reviewed the manuscript. All authors read and approved the final manuscript.

\section{Funding}

Research was founded by National Science Centre Poland Grant no: 2017/26/M/NZ5/01184 (Novel, two-stage delivery, nanohydroxyapatite (nHAp) -iron oxide (Fe2O3/Fe3O4) - miRNA scaf-fold with controlled by static magnetic field payload release for osteo-porotic bone fracture regeneration).

\section{Availability of data and materials}

The datasets used and/or analysed during the current study are available from the corresponding author on reasonable request.

\section{Ethics approval and consent to participate}

Not applicable.

Consent for publication

Not applicable.

Competing interests

The authors declare that they have no competing interests. 


\begin{abstract}
Author details
${ }^{1}$ Institute of Physics, Polish Academy of Sciences, 02668 Warsaw, Poland. 2 Department of Experimental Biology, Faculty of Biology and Animal Science, Wrocław University of Environmental and Life Sciences, Norwida 27B, 50-375 Wrocław, Poland. ${ }^{3}$ Cardinal Stefan Wyszynski University, Collegium Medicum, 01938 Warsaw, Poland. ${ }^{4}$ International Institute of Translational Medicine, Jesionowa 11, Malin, Wisznia Mała, 55-114 Wrocław, Poland.
\end{abstract}

Received: 6 May 2020 Accepted: 9 September 2020

Published online: 15 September 2020

\section{References}

1. Miller RR, Roubenoff R. emerging interventions for elderly patients-the promise of regenerative medicine. Clin Pharmacol Ther. 2019;105:53-60.

2. Akkawi I, Zmerly H. Osteoporosis: Current Concepts. Joints. 2018;6:122-7.

3. Hernlund E, Svedbom A, Ivergård M, Compston J, Cooper C, Stenmark $J$, et al. Osteoporosis in the European Union: medical management, epidemiology and economic burden. A report prepared in collaboration with the International Osteoporosis Foundation (IOF) and the European Federation of Pharmaceutical Industry Associations (EFPIA). Arch Osteoporos. 2013:8:136

4. Prakasam M, Locs J, Salma-Ancane K, Loca D, Largeteau A, BerzinaCimdina L. Biodegradable materials and metallic implants-a review. J Funct Biomater. 2017; (cited 2020 May 3); 8. https://www.ncbi.nlm.nih. gov/pmc/articles/PMC5748551/.

5. Prasad K, Bazaka O, Chua M, Rochford M, Fedrick L, Spoor J, et al. Metallic biomaterials: current challenges and opportunities. Materials (Basel). 2017; (cited 2020 May 3); 10. https://www.ncbi.nlm.nih.gov/pmc/artic les/PMC5578250/.

6. Eliaz N. Corrosion of Metallic biomaterials: a review. Materials (Basel). 2019; (cited 2020 May 3). 12. https://www.ncbi.nlm.nih.gov/pmc/artic les/PMC6384782/.

7. Oviroh PO, Akbarzadeh R, Pan D, Coetzee RAM, Jen T-C. New development of atomic layer deposition: processes, methods and applications. Sci Technol Adv Mater. 2019;20:465-96.

8. Im H, Wittenberg NJ, Lindquist NC, Oh S-H. Atomic layer deposition (ALD): a versatile technique for plasmonics and nanobiotechnology. J Mater Res. 2012;27:663-71.

9. Suntola T. Atomic Layer Epitaxy. Espo: Microchemistry Ltd; 1989.

10. Knez M, Nielsch K, Niinistö L. Synthesis and surface engineering of complex nanostructures by atomic layer deposition. Advanced Materials. 2007. p. 3425-38.

11. Miikkulainen V, Leskelä M, Ritala M, Puurunen RL. Crystallinity of inorganic films grown by atomic layer deposition: overview and general trends. J Appl Phys. 2013;113:021301.

12. Knez M. Application of ALD to biomaterials and biocompatible coatings. Atomic layer deposition of nanostructured materials. Weinheim: Wiley-VCH Verlag GmbH \& Co. KGaA; 2012. p. 301-25.

13. Graniel O, Weber M, Balme S, Miele P, Bechelany M. Biosensors and bioelectronics atomic layer deposition for biosensing applications. Biosens Bioelectronic. 2018;122:147-59.

14. Seweryn A, Pielok A, Lawniczak-Jablonska K, Pietruszka R, Marcinkowska K, Sikora M, et al. Zirconium oxide thin films obtained by atomic layer deposition technology abolish the anti-osteogenic effect resulting from miR-21 inhibition in the pre-osteoblastic MC3T3 cell line. Int J Nanomed. 2020;15:1595-610.

15. Marycz K, Sobierajska P, Roecken M, Kornicka-Garbowska K, Kępska $M$, Idczak R, et al. Iron oxides nanoparticles (IOs) exposed to magnetic field promote expression of osteogenic markers in osteoblasts through integrin alpha-3 (INTa-3) activation, inhibits osteoclasts activity and exerts anti-inflammatory action. J Nanobiotechnol. 2020;18:33.

16. Marycz K, Grzesiak J, Wrzeszcz K, Golonka P. Adipose stem cell combined with plasma-based implant bone tissue differentiation in vitro and in a horse with a phalanx digitalis distalis fracture: a case report. Veterinarni Medicina (Czech Republic) [Internet]. 2012

17. Rudenja S, Minko A, Buchanan DA. Low-temperature deposition of stoichiometric $\mathrm{HfO} 2$ on silicon: analysis and quantification of the $\mathrm{HfO}$ 2/Si interface from electrical and XPS measurements. Appl Surf Sci. 2010;257:17-21.
18. Crist BV. Handbooks of monochromatic XPS Spectra. XPS International LLC: Handbooks of monochromatic XPS spectra; 2005.

19. Sokolov AA, Filatova EO, Afanas' Ev VV, Taracheva EY, Brzhezinskaya MM, Ovchinnikov AA. Interface analysis of HfO2 films on (1 0 0) Si using X-ray photoelectron spectroscopy. J Phys D Appli Phys. 2008;42:035308.

20. Wang J-X, Jia X-J, Liu Y, Dong J-H, Ren X-M, Xu O, et al. Silencing of miR-17-5p suppresses cell proliferation and promotes cell apoptosis by directly targeting PIK3R1 in laryngeal squamous cell carcinoma. Cancer Cell Int. 2020;20:14

21. Li S, Lv X, Zhai K, Xu R, Zhang Y, Zhao S, et al. MicroRNA-7 inhibits neuronal apoptosis in a cellular Parkinson's disease model by targeting Bax and Sirt2. Am J Transl Res. 2016;8:993-1004.

22. Smieszek A, Marcinkowska K, Pielok A, Sikora M, Valihrach L, Marycz K. The Role of miR-21 in osteoblasts-osteoclasts coupling in vitro. Cells. 2020;9:479

23. Mencía Castaño I, Curtin CM, Duffy GP, O’Brien FJ. Harnessing an inhibitory role of miR-16 in osteogenesis by human mesenchymal stem cells for advanced scaffold-based bone tissue engineering. Tissue Eng Part A. 2019;25:24-33.

24. Gieraltowska S, Wachnicki L, Witkowski BS, Mroczynski R, Dluzewski P, Godlewski M. Characterization of dielectric layers grown at low temperature by atomic layer deposition. Thin Solid Films. 2015;577:97-102.

25. Bang SM, Moon HJ, Kwon YD, Yoo JY, Pae A, Kwon IK. Osteoblastic and osteoclastic differentiation on SLA and hydrophilic modified SLA titanium surfaces. Clin Oral Implant Res. 2014;25:831-7.

26. Zhang X-Y, Hsu C-H, Lien S-Y, Wu W-Y, Ou S-L, Chen S-Y, et al. Temperature-dependent $\mathrm{HfO} 2 / \mathrm{Si}$ interface structural evolution and its mechanism. Nanoscale Res Lett. 2019; (cited 2020 May 3). 14. https://www.ncbi. nlm.nih.gov/pmc/articles/PMC6405792/.

27. Xu J, Wen M, Zhao X, Liu L, Song X, Lai P-T, et al. Effects of HfO2 encapsulation on electrical performances of few-layered MoS2 transistor with ALD HfO2 as back-gate dielectric. Nanotechnology. 2018;29:345201.

28. Liu L, Bhatia R, Webster TJ. Atomic layer deposition of nano-TiO 2 thin films with enhanced biocompatibility and antimicrobial activity for orthopedic implants. Int J Nanomed. 2017;12:8711-23.

29. Godlewski M, Gierałtowska S, Wachnicki $Ł$, Pietuszka R, Witkowski BS, Słońska A, et al. High-k oxides by atomic layer deposition-applications in biology and medicine. J Vacuum Sci Technol A. 2017;35:021508.

30. Fohlerova Z, Mozalev A. Anodic formation and biomedical properties of hafnium-oxide nanofilms. J Mater Chem B R Soc Chem. 2019:7:2300-10.

31. Marill J, Mohamed Anesary N, Paris S. DNA damage enhancement by radiotherapy-activated hafnium oxide nanoparticles improves cGASSTING pathway activation in human colorectal cancer cells. Radiother Oncol. 2019;141:262-6.

32. Field JA, Luna-Velasco A, Boitano SA, Shadman F, Ratner BD, Barnes C, et al. Cytotoxicity and physicochemical properties of hafnium oxide nanoparticles. Chemosphere. 2011:84:1401-7.

33. Charles JF, Aliprantis AO. Osteoclasts: more than 'bone eaters'. Trends Mol Med. 2014:20:449-59.

34. Wang X, Li Z, Bai J, Song W, Zhang F. miR-17-5p regulates the proliferation and apoptosis of human trabecular meshwork cells by targeting phosphatase and tensin homolog. Molecular Medicine Reports. Spandidos Publications. 2019:19:3132-8.

35. Jia J, Feng $X, X u$ W, Yang S, Zhang Q, Liu X, et al. MiR-17-5p modulates osteoblastic differentiation and cell proliferation by targeting SMAD7 in non-traumatic osteonecrosis. Exp Mol Med. 2014;46:e107.

36. Guido G, Scaglione M, Fabbri L, Ceglia MJ. The "osteoporosis disease". Clin Cases Miner Bone Metab. 2009:6:114-6.

37. Ling M, Huang P, Islam S, Heruth DP, Li X, Zhang LQ, et al. Epigenetic regulation of Runx2 transcription and osteoblast differentiation by nicotinamide phosphoribosyltransferase. Cell Biosci. 2017;7:27.

38. Komori T. Regulation of osteoblast differentiation by Runx2. Adv Exp Med Biol. 2010;658:43-9.

39. Kawane $T$, Oin $X$, Jiang $Q$ Miyazaki T, Komori $H$, Yoshida CA, et al. Runx2 is required for the proliferation of osteoblast progenitors and induces proliferation by regulating Fgfr2 and Fgfr3. Sci Rep. 2018:8:1-17.

40. Komori T. Regulation of Proliferation, Differentiation and Functions of Osteoblasts by Runx2. Int J Mol Sci. 2019 (cited 2020 Apr 1);20. https:// www.ncbi.n/m.nih.gov/pmc/articles/PMC6480215/. 
41. Moser SC, van der Eerden BCJ. Osteocalcin - a versatile bone-derived hormone. Front Endocrinol (Lausanne). 2019 (cited 2020 May 3);9. https:// www.ncbi.nlm.nih.gov/pmc/articles/PMC6335246/.

42. Zupan J, Jeras M, Marc J. Osteoimmunology and the influence of pro-inflammatory cytokines on osteoclasts. Biochem Med (Zagreb). 2013;23:43-63.

43. Ginaldi L, Di Benedetto MC, De Martinis M. Osteoporosis, inflammation and ageing. Immun Ageing. 2005;2:14.

44. Edwards CJ, Williams E. The role of interleukin-6 in rheumatoid arthritisassociated osteoporosis. Osteoporos Int. 2010;21:1287-93.

45. Leskelä M, Ritala M. Atomic layer deposition (ALD): from precursors to thin film structures. Thin Solid Films. 2002;409:138-46.

46. Amano $S$, Chang Y-T, Fukui Y. ERK5 activation is essential for osteoclast differentiation. PLoS ONE. 2015;10:e0125054

47. Starosta R, Brzuszkiewicz A, Bykowska A, Komarnicka UK, Bażanów B, Florek $M$, et al. A novel copper(I) complex, [Cul(2,2'-biquinoline) $\mathrm{P}(\mathrm{CH} 2 \mathrm{~N}(\mathrm{CH} 2 \mathrm{CH} 2) 2 \mathrm{O}) 3]$ - Synthesis, characterisation and comparative studies on biological activity. Polyhedron. 2013:50:481-9

48. Doubling Time-online computing with 2 points. (cited 2018 Oct 3). http://www.doubling-time.com/compute.php.

49. Marycz K, Kornicka K, Grzesiak J, Śmieszek A, Szłapka J. Macroautophagy and Selective Mitophagy Ameliorate Chondrogenic Differentiation
Potential in Adipose Stem Cells of Equine Metabolic Syndrome: New Findings in the Field of Progenitor Cells Differentiation [Internet]. Oxidative Medicine and Cellular Longevity. 2016 [cited 2019 Jun 27]

50. Chomczynski P, Sacchi N. Single-step method of RNA isolation by acid guanidinium thiocyanate-phenol-chloroform extraction. Anal Biochem. 1987;162:156-9.

51. Nawrocka D, Kornicka K, Śmieszek A, Marycz K. Spirulina platensis Improves Mitochondrial Function Impaired by Elevated Oxidative Stress in Adipose-Derived Mesenchymal Stromal Cells (ASCs) and Intestinal Epithelial Cells (IECS), and Enhances Insulin Sensitivity in Equine Metabolic Syndrome (EMS) Horses. Mar Drugs [Internet]. 2017

52. Livak KJ, Schmittgen TD. Analysis of relative gene expression data using real-time quantitative PCR and the 2(-Delta Delta $C(T)$ ) Method. Methods. 2001:25:402-8.

\section{Publisher's Note}

Springer Nature remains neutral with regard to jurisdictional claims in published maps and institutional affiliations.
Ready to submit your research? Choose BMC and benefit from:

- fast, convenient online submission

- thorough peer review by experienced researchers in your field

- rapid publication on acceptance

- support for research data, including large and complex data types

- gold Open Access which fosters wider collaboration and increased citations

- maximum visibility for your research: over $100 \mathrm{M}$ website views per year

At BMC, research is always in progress.

Learn more biomedcentral.com/submissions 